\title{
Vitamin D3 Supplementation Improved Physical Performance in Healthy Older Adults in Japan: A Pilot Study
}

\author{
Noboru Hasegawa1, Miyako Mochizuki², Mayumi Kato ${ }^{3}$, Nobuko Shimizu${ }^{1}$, Takako Yamada4 \\ ${ }^{1}$ Department of Health and Medical Sciences, Ishikawa Prefectural Nursing University, Kahoku, Japan \\ ${ }^{2}$ Kyoto Bunkyo Junior College, Uji, Japan \\ ${ }^{3}$ Aichi Medical College for Physical and Occupational Therapy, Kiyosu, Japan \\ ${ }^{4}$ Bukkyo University, Kyoto, Japan \\ Email: hsgwn@ishikawa-nu.ac.jp
}

How to cite this paper: Hasegawa, N. Mochizuki, M., Kato, M., Shimizu, N. and Yamada, T. (2018) Vitamin D3 Supplementation Improved Physical Performance in Healthy Older Adults in Japan: A Pilot Study. Health, 10, 1200-1209.

https://doi.org/10.4236/health.2018.109092

Received: August 24, 2018

Accepted: September 16, 2018

Published: September 19, 2018

Copyright (c) 2018 by authors and Scientific Research Publishing Inc. This work is licensed under the Creative Commons Attribution International License (CC BY 4.0).

http://creativecommons.org/licenses/by/4.0/

\section{Open Access}

\begin{abstract}
Japan has the highest proportion of older adults and so-called "Super-aged society" in the world. These results suggested that the prevalence of both cognitive and physical functional impairment increases with age. Therefore, the present study was designed to investigate the effect of vitamin D3 supplementation in cognitive and physical functional impairment in healthy older adults in Japan. We enrolled 7 Japanese male (age: $76.0 \pm 8.7$ ) and 5 female (age: $78.3 \pm 9.3$ ) in this study. The physical function of even a person getting on a wheelchair could be tested in all subjects. Treatment group $(n=7)$ consisted of a $500 \mathrm{IU} /$ day vitamin D3 corresponding to twice of daily requirement for 6 months. Blood was collected by venipuncture and the serum 25-hydroxy vitamin D (25 OHD), 1,25-hydroxy vitamin D (1,25 OHD), Ca and PTH concentration were measured. The Mini-Mental State Examination and the Montreal Cognitive Assessment-Japanese version were used for the cognitive function test. Physical function was measured objectively using the Timed Up and Go (TUG), 4-mgait speed test (4 MGS), 5-repetition sit-to-stand (5 STS), 30-second chair stand test (CS-30) and measurement of upper grip strength. Our results show that a 6-month intake of vitamin D3 increased serum $25 \mathrm{OHD}$ within the insufficiency and sufficiency levels without changing 1,25 $\mathrm{OHD}, \mathrm{Ca}$ and $\mathrm{PTH}$ concentration. And it significantly decreased 4 MGS without changing TUG, 5 STS, CS-30, upper grip strength and cognitive function. Serum 25 OHD cut-off values for skeletal muscle index, grip strength and $4 \mathrm{MGS}$ in diagnosis of sarcopenia are $18.6-23.4 \mathrm{ng} / \mathrm{mL}$. These findings suggest that serum 25 OHD levels $(23.4 \mathrm{ng} / \mathrm{mL})$ might improve moving capacity, lower limb muscle strength, and physical balance functional
\end{abstract}


impairment.

\section{Keywords}

Serum 25-Hydroxyvitamin D, Cognitive Function, Physical Function, Aging, Sarcopenia

\section{Introduction}

Vitamin D is a secosteroid associated with peripheral calcium homeostasis [1]. Vitamin D is available in vitamin D2 of plants and D3 of animals. Both vitamin D2 and D3 are biologically inert and require activation through two hydroxylation processes involving 25-hydrooxylase (CYP2R1) and $1 \alpha$-hydroxylase (CYP27B1), located in the liver and kidney, respectively [2]. 1,25-dihydroxyvitamin D (1,25 $\mathrm{OHD}$ ) is a biologically active metabolite produced by two steps of hydroxylation reactions [3].

Recent evidence has identified a beneficial role of vitamin $\mathrm{D}$ in maintaining cognitive and physical functions. Vitamin D receptor and CYP27B1 have been found in the brain (hippocampus) [4] and skeletal muscle [5]. Over expression of reactive oxygen species (ROS) stimulated by disruption of cerebral blood flow is one of the main causes of vascular dementia-induced cognitive deficits in the rat model [6]. 1,25 OHD was reported to have a significant physiological antioxidant activity [7].

The low 25-hydroxy vitamin D (25 OHD) level has been recently associated with greater risk of cognitive impairment in older as well as younger adults using the Montreal Cognitive Assessment (MoCA) Arabic version [8]. Vitamin D supplementation caused significant improvement in the cognitive performance by Mini-Mental State Examination (MMSE) score in Alzheimer's disease [9]. Lower serum $25 \mathrm{OHD}$ is associated with poorer functional mobility using walking speed, Timed Up and Go test (TUG), and cognitive function using MMSE [10]. Vitamin D3 supplementation improves muscle function and physical performance in the elderly population using 4 meter gait speed test (4 MGS) [11]. In our latest study, a significant positive correlation was found between urinary 25 $\mathrm{OHD} /$ creatinine and MMSE or Japanese version of the MoCA (MoCA-J), and a significant negative correlation between serum 1,25 OHD and TUG or 4 MGS [12]. Other studies, however, have not found an association between vitamin D and physical performance [13] [14] [15] [16] [17]. Vitamin D supplementation has not been found to increase muscle strength in older adults [18] [19] [20] [21].

Therefore, the present study was designed to investigate the effect of vitamin D3 supplementation corresponding to twice of the daily requirement for 6 months in cognitive and physical functional impairment in healthy older adults in Japan. 


\section{Methods}

\subsection{Subjects and Setting}

Prior to the study, the ethical approval was obtained from the ethics committee of Kyoto Bunkyo Junior College (project registration number in 2016: 7) and Aichi Medical College for Physical and Occupational Therapy (Project registration number in 2016: 468). A total of 12 healthy adults age $\geq 65$ years were included in adult day-care center clients in Fukui $(\mathrm{n}=4)$ and Aichi Prefectures ( $\mathrm{n}$ $=8$ ). These areas with varying daylight hours were selected. The annual daylight hours were maximum in Aichi (2255 hrs/year: the 4th in Japan), and minimum in Fukui (1788 hrs/year: the 37th in Japan) between the two areas. The researchers attended the adult day-care center and assured the proper management of safety hand confidentiality of the study. Eligible participants were required to not have had sarcopenia, osteoporosis and functional disorder of thyroid. The manager of the adult day-care center invited participation in the study, and all the subjects whose participation was requested were selected from September in 2017 to May in 2018. After obtaining informed consent from a family member belonging to the same household, we enrolled 7 Japanese male (age: $80.8 \pm 6.1$ ) and 5 female (age: $75.9 \pm 7.5$ ) in this study. The physical function of even a person getting on a wheelchair could be tested among all subjects. All the participants eat at home. Treatment group $(n=7)$ consisted of a vitamin D supplements (500 IU/day of the vitamin D3 purchased from UHA Mikakuto Co., Ltd., Osaka) for 6 months. The hypercalcemia at vitamin D intake level is lower than 10,000 IU/day (Dietary Reference Intake for Japanese, 2015).

\subsection{Cognitive Function Test}

The MMSE was used for the cognitive function test. It consists of five downstream items of orientation, memory, attentiveness for calculations, speech function, and design capacity. The maximum score for the MMSE is 30 points, and cutoff score for dementia were of 23 to 24 points [22]. The MoCA-J may be better at detecting early cognitive dysfunction [23] and was used for the cognitive function test. The maximum score for the MoCA-J is 30 points, and cutoff score for dementia were of 25 to 26 points [9]. These tests were performed by verbal questioning of 5- to 10-min duration by skilled occupational and physical therapists.

\subsection{Muscle Weight and Physical Function}

Muscle weight was measured using Inbody 430 (Inbody Japan, Tokyo) and calculated as skeletal muscle index (SMI). Physical performance tests included balance, lower limbs muscular strength, 4 MGS and upper grip strength. The TUG of functional mobility is assessed by asking the participant to stand up from a standard chair, walk a 3 meter distance, turn, walk back to the chair and sit down again [24]. The lower limbs muscular strength was measured against the time to complete 5-repetition sit-to-stand (5 STS) and the number to chair stand 
for $30 \mathrm{sec}$ (CS-30) [25]. All tests were performed by skilled physical therapists.

\subsection{Serum 1,25 OHD, 25 OHD, Ca and PTH Assay}

Blood was collected by venipuncture and serum 1,25 OHD, $25 \mathrm{OHD}, \mathrm{Ca}$ and PTH concentration were measured by Nikken Igaku Co. (Fukui, Japan) and Falco Holdings Co. (Kyoto, Japan).

\subsection{Statistics}

Results are expressed as the mean \pm S.D., and differences between before and after intervention with vitamin D3 supplements were evaluated using the Wilcoxon test. A $p$-value $<0.05$ was considered to be statistically significant. Analyses were carried out using SPSS 21 for Windows (IBM, Japan).

\section{Results}

\subsection{Study Subjects}

Characteristics of the study subjects are shown in Table 1 . Mean age was 76.0 years for males $(n=7)$ and 78.3 years for females $(n=5)$. Obesity was defined as a body-mass index (BMI) $\geq 25.0 \mathrm{~kg} / \mathrm{m}^{2}$. The prevalence of obesity defined BMI was $0 \%$ in males and $26.7 \%$ in females ( 2 subjects in each group).

\subsection{Change in Serum $25(\mathrm{OH}) \mathrm{D}, 1,25(\mathrm{OH}) \mathrm{D}$, Ca and PTH}

A 6 month intake of vitamin D3 supplements significantly increased serum 25 OHD concentration within the insufficiency and sufficiency level ( 3 subjects: $>20$ $\mathrm{ng} / \mathrm{mL}$ and $<30 \mathrm{ng} / \mathrm{mL}, 3$ subjects: $>30 \mathrm{ng} / \mathrm{mL}$ ) without changing serum $\mathrm{Ca}$ and PTH concentration (Figure 1). These parameters in control group were not changed for 6 months. These results suggested that vitamin D3 supplements intake maintained serum 25 OHD levels.

\subsection{Serum 25 OHD and Cognitive Function}

Significant changes in cognitive function in supplementation and control groups were not seen (Figure 2). These findings suggest that vitamin D3 supplementation was not associated with change in cognitive function.

\subsection{Serum 25 OHD and Physical Function}

Vitamin D3 supplementation decreased 4 MGS without changing TUG, 5 STS, CS-30 and upper grip strength (Figure 3). These findings suggest that serum 25 OHD levels might improve moving capacity, lower limb muscle strength, and physical balance functional impairment.

\subsection{Serum 25 OHD Cut-Off Values for Diagnosis of Sarcopenia}

The cut-off values of each test types for the diagnosis of sarcopenia are shown in Table 2. From the correlation coefficient and $p$-values, serum 25 OHD cut-off values are calculated. These cut-off values were $18.6-23.4 \mathrm{ng} / \mathrm{mL}$. 
VD3 Supplementation group
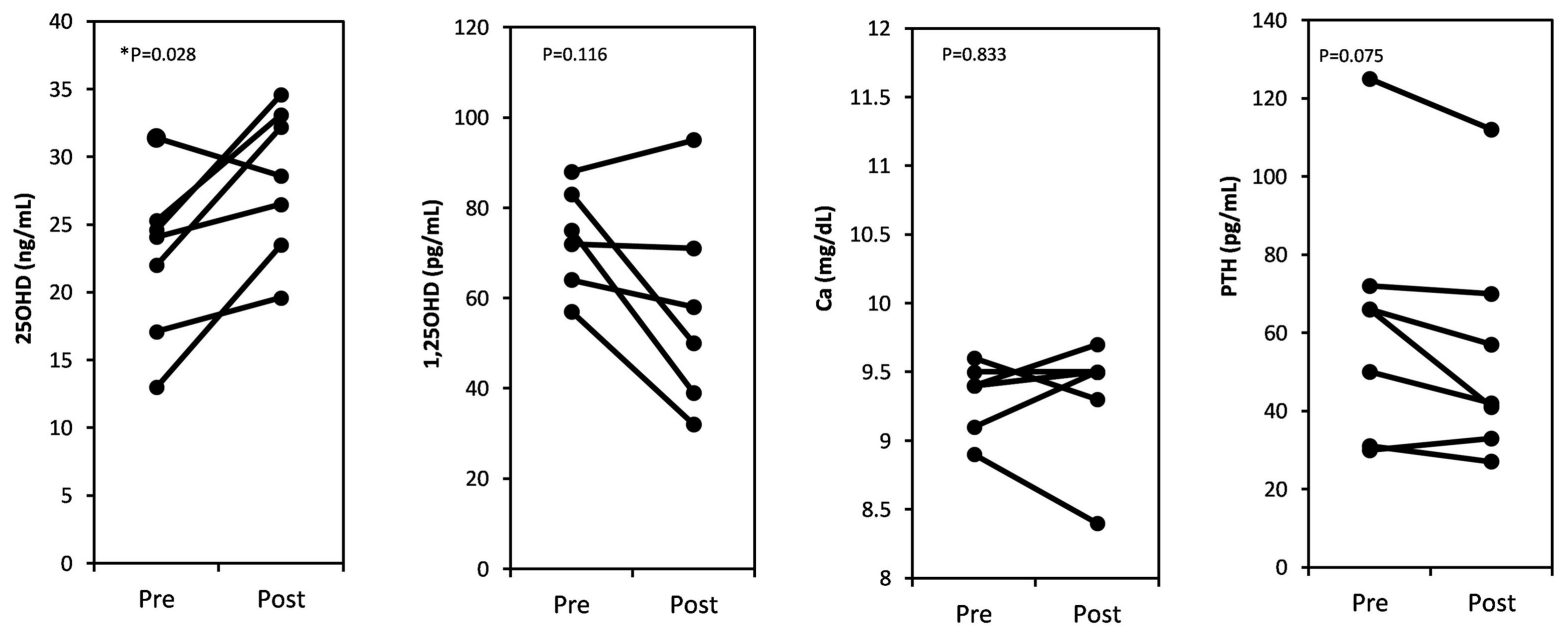

Control group
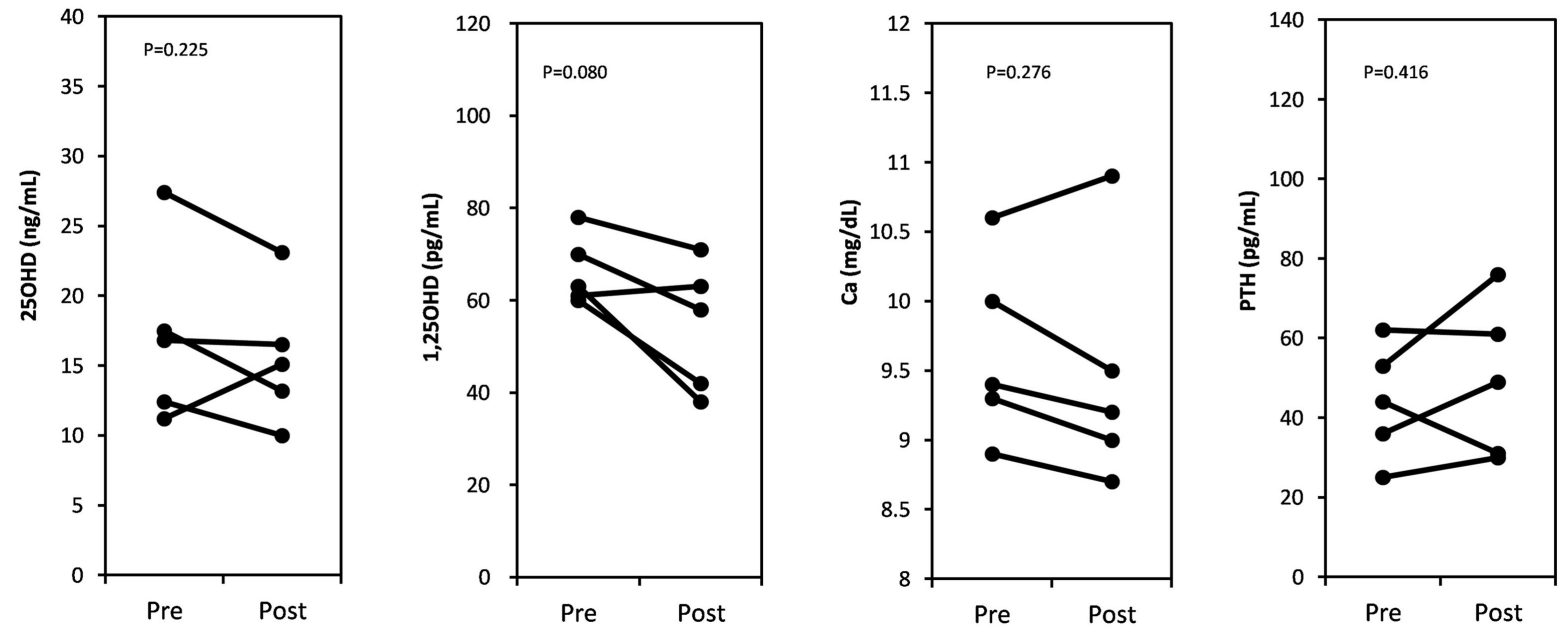

Figure 1. Effects of vitamin D3 supplementation on serum biological parameter. ${ }^{\star}, p$-value $<0.05$ was considered to be statistically significant.

VD3 Supplementation group

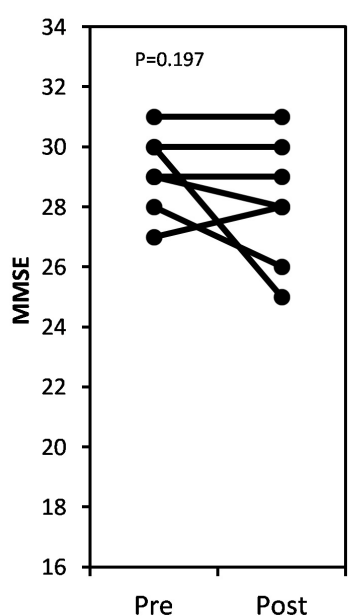

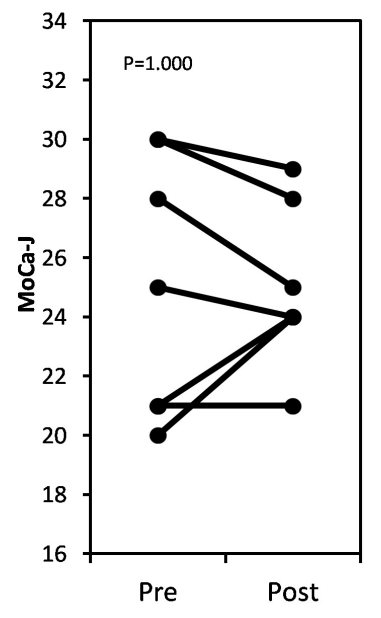

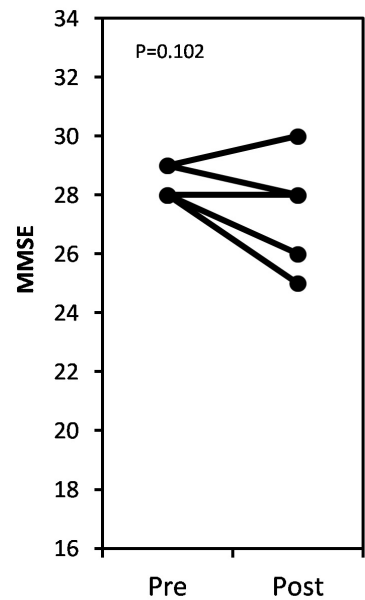

Figure 2. Effects of vitamin D3 supplementation on cognitive function. 
VD3 Supplementation group
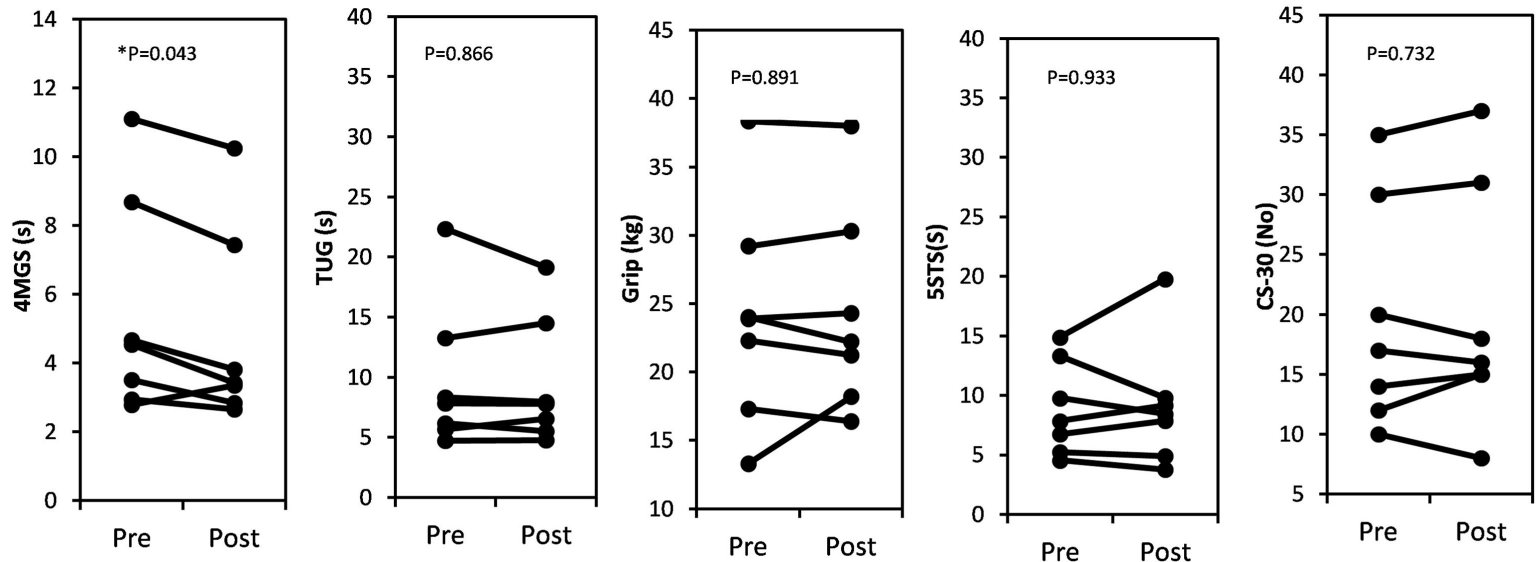

Control group
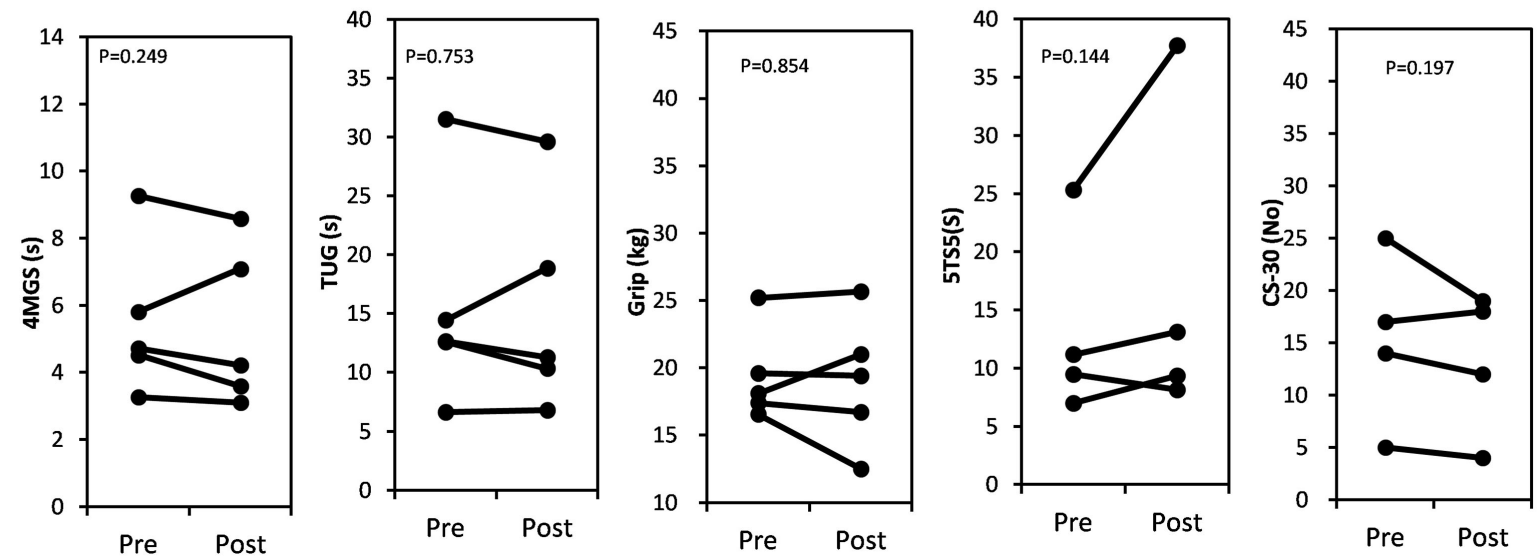

Figure 3. Effects of serum $25 \mathrm{OHD}$ on physical function. ${ }^{*}$, $p$-value $<0.05$ was considered to be statistically significant.

Table 1. Characteristics of the study subjects.

\begin{tabular}{ccc}
\hline & VD3 Supplementation group & Control group \\
\hline No. of participants (\% male) & $7(33.3)$ & $5(40.0)$ \\
Age (y) & $77.8 \pm 8.5$ & $77.6 \pm 5.0$ \\
Body height $(\mathrm{cm})$ & $156.2 \pm 7.8$ & $152.4 \pm 3.6$ \\
Body weight $(\mathrm{kg})$ & $55.9 \pm 9.8$ & $56.2 \pm 9.4$. \\
BMI $\left(\mathrm{kg} / \mathrm{m}^{2}\right)$ & $22.8 \pm 2.8$ & $24.3 \pm 4.3$ \\
\hline
\end{tabular}

Table 2. Serum 25 OHD cut-off values for physical functions in diagnosis of sarcopenia.

\begin{tabular}{cccc}
\hline Test types & $\begin{array}{c}\text { Test cut-off } \\
\text { values }\end{array}$ & $\begin{array}{c}\text { Correlation coefficient } \\
\text { and } p \text { values between test } \\
\text { and serum 25 OHD }\end{array}$ & $\begin{array}{c}\text { Serum 25 OHD cut-off } \\
\text { values (ng/mL) }\end{array}$ \\
\hline Grip strength (female) & $<20 \mathrm{~kg}^{27)}$ & $0.522 / 0.038$ & 18.6 \\
4 MGS (s) & $<5 \mathrm{sec}^{13)}$ & $-0.58 / 0.003$ & 23.4 \\
\hline
\end{tabular}




\section{Discussion}

In the present study, the number of the vitamin D3 supplement group with 25 $\mathrm{OHD}>30 \mathrm{ng} / \mathrm{mL}$ (normal) increased from 1 to 3 and the number of vitamin D3 supplement group with $25 \mathrm{OHD}<20 \mathrm{ng} / \mathrm{mL}$ (deficient) decreased from 2 to 1 during 6 months vitamin $\mathrm{D}$ supplementation. These data showed that vitamin D3 supplementation was associated with improvement of serum vitamin D levels and the vitamin D3 dose used in the intervention (500 IU/day) was low for typical improvement of cognitive and physical functions.

In the present study, vitamin D3 supplementation significantly decreased 4 MGS without changing 5 STS, TUG and cognitive function. The effect of vitamin D3 on 4 MGS was especially clear. However, vitamin D3 was not associated with change in CS-30. These results suggested that vitamin D3 was found to improve moving capacity, but not endurance. The cut-off values for predicting the level of risk of falls in community-dwelling elders are $1.0 \mathrm{~m} / \mathrm{sec}$ in $4 \mathrm{~m}$ walking speed [26]. The number of vitamin D3 supplement group with 4 MGS $>4$ sec decreased 4 to 2 during 6 months vitamin D3 supplementation. Vitamin D bound vitamin D receptor in skeletal muscle and increased mitochondria function [27]. The functional decline of the nervous system would greatly affect the decrease of walking speed in elderly with weaker muscular strength [28]. These findings suggest that serum 25 OHD levels could contribute to improve neuro-muscular system and physical performance.

In 1989, Rosenberg proposed the term "sarcopenia" to describe age-related decrease of muscle mass [29]. Sarcopenia represents an important risk factor for disability and mortality. Vitamin D deficiency appears to enhance intramuscular adipose tissue impacting as reduced functionality in skeletal tissues [30]. These findings suggested that vitamin D affects skeletal muscle mass and morphology. Sarcopenia still has no broadly accepted clinical definition. But in this study subjects (77.6 \pm 7.4 years), 9 (75\% of subjects) have values lower than sarcopenia diagnostic criteria (muscle weight, upper grip strength and walking speed). In the present study, the cut-off values of serum 25 OHD for the diagnosis of sarcopenia were 18.6 - $23.4 \mathrm{ng} / \mathrm{mL}$. Our results suggested that maintained $25 \mathrm{OHD}$ levels above $23.4 \mathrm{ng} / \mathrm{mL}$ prevent sarcopenia in the elderly.

Recent evidence suggests a potential beneficial role of vitamin D in maintaining cognitive function [31]. However, prospective studies have not found an association between $25 \mathrm{OHD}$ concentration and cognitive function. In the present study, daily $500 \mathrm{IU}$ vitamin D3 (serum $25 \mathrm{OHD} \leq 30 \mathrm{ng} / \mathrm{mL}$ ) supplementation was not associated with change in cognitive function. These results suggested that the threshold value for improvement of physical function is lower than that for improvement of cognitive function.

Further study of optimal 25 OHD levels for maintaining physical, cognitive function and preventing falls is needed.

The limitation of this study includes small sample size and possible selection bias. Further subjects are needed. 


\section{Acknowledgements}

This work was supported by JSPS KAKENHI Grant Number JP22500682.

\section{Conflicts of Interest}

The authors declare no conflicts of interest regarding the publication of this paper.

\section{References}

[1] DeLuca, G.C., Kimball, S.M., Kolasinski, J., Ramagopalan, S.V. and Ebers, G.C. (2013) The Role of Vitamin D in Nervous System Health and Disease. Neuropathology and Applied Neurobiology, 39, 458-484. https://doi.org/10.1111/nan.12020

[2] Holick, M.F. (2007) Vitamin D Deficiency. New England Journal of Medicine, 357, 266-281. https://doi.org/10.1056/NEJMra070553

[3] Garcion, E., Wion-Barbot, N., Montero-Menei, C.N., Berger, F. and Wion, D. (2002) New Clues about Vitamin D Functions in the Nervous System. Trends in Endocrinology and Metabolism, 13, 100-105.

https://doi.org/10.1016/S1043-2760(01)00547-1

[4] Eyles, D.W., Smith, S., Hewison, M. and McGrath, J.J. (2005) Distribution of the Vitamin D Receptor and 1 Alpha-Hydroxylase in Human Brain. Journal of Chemical Neuroanatomy, 29, 21-30. https://doi.org/10.1016/j.jchemneu.2004.08.006

[5] Rachele, M.P., Lisa, C., Karl, O., Thomas, G., Alice, H.L., Bess, D.-H. and Roger, A.F. (2015) Effect of 1,25-Dihydroxyvitamin D3 and Vitamin D2 of the Expression of the Vitamin D Receptor in Human Skeletal Muscle Cells. Calcified Tissue International, 96, 256-253. https://doi.org/10.1007/s00223-014-9932-x

[6] Li, Z., Wang, Y., Xie, Y., Yang, Z. and Zhang, T. (2011) Protective Effects of Exogenous Hydrogen Sulfide on Neurons of Hippocampus in a Rat Model of Brain Ischemia. Neurochemical Research, 36, 1840-1849.

https://doi.org/10.1007/s11064-011-0502-6

[7] Calgaroto, N.S., Thomé, G.R., da Costa, P., Baldissareli, J., Hussein, F.A. and Schmats, R. (2014) Effect of Vitamin D3 on Behavioral and Biochemical Parameters in Diabetes Type 1-Induced Rats. Cell Biochemistry and Function, 32, 502-510. https://doi.org/10.1002/cbf.3044

[8] Darwish, H., Zeinoun, P., Ghusn, H., Khoury, B., Tamim, H. and Khoury, S.J. (2015) Serum 25-Hydroxyvitamin D Predicts Cognitive Performance in Adults. Neuropsychiatric Disease and Treatment, 11, 2217-2223. https://doi.org/10.2147/NDT.S87014

[9] Gangwar, A.K., Rawat, A., Tiwari, S., Tiwari, S.C., Narayan, J. and Tiwari, S. (2015) Role of Vitamin-D in the Prevention and Treatment of Alzheimer's Disease. Indian Journal of Physiology and Pharmacology, 59, 94-99.

[10] Gschwind, Y.J., Bischoff-Ferrari, H.A., Bridenbaugh, S.A., Härdi, I. and Kressig, R.W. (2014) Association between Serum Vitamin D Status and Functional Mobility in Memory Clinic Patient Aged 65 Years and Older. Gerontology, 60, 123-129. https://doi.org/10.1159/000355667

[11] Lagari, V., Gómez-Marín, O. and Levis, S. (2013) The Role of Vitamin D in Improving Physical Performance in the Elderly. Journal of Bone and Mineral Research, 28, 2194-2201. https://doi.org/10.1002/jbmr.1949

[12] Hasegawa, N., Mochizuki, M., Kato, M., Yamada, T., Shimizu, N. and Torii, A. 
(2016) Serum 1,25-Hydroxyvitamin D: A Useful Index of Cognitive and Physical Functional Impairment in Healthy Older Adults in Japan: A Pilot Study. Health, 8, 1679-1686. https://doi.org/10.4236/health.2016.815163

[13] Verreault, R., Semba, R.D., Volphato, S., Ferrucci, L., Fried, L.P. and Guralnik, J.M. (2002) Low Serum Vitmin D Does Not Predict New Disability or Loss of Muscle Strength in Older Women. Journal of the American Geriatrics Society, 50, 912-917. https://doi.org/10.1046/j.1532-5415.2002.50219.x

[14] Faulkner, K.A., Cauley, J.A., Zmuda, J.M., Landsittel, D.P., Newman, A.B., Studenski, S.A., et al. (2006) Higher 1,25-Dihydroxyvitamin D3 Concentrations Associated with Lower Fall Rates in Older Community-Dwelling Women. Osteoporosis International, 17, 1318-1328. https://doi.org/10.1007/s00198-006-0071-8

[15] Bartali, B., Frongillo, E.A., Guralnik, J.M., et al. (2008) Serum Micronutrient Concentrations and Decline in Physical Function among Older Persons. JAMA, 299, 308-315. https://doi.org/10.1001/jama.299.3.308

[16] Chan, R., Chan, D., Woo, J., et al. (2012) Not All Elderly People Benefit from Vitamin D Supplementation with Respect to Physical Function: Results from the Osteoporotic Fractures in Men Study, Hong Kong. Journal of the American Geriatrics Society, 60, 290-295. https://doi.org/10.1111/j.1532-5415.2011.03789.x

[17] Sohl, E., De Jongh, R.T., Heijboere, A.C., et al. (2013) Vitamin D Status Is Associated with Physical Performance: The Results of Three Independent Cohorts. Osteoporosis International, 24, 187-196. https://doi.org/10.1007/s00198-012-2124-5

[18] Dhesi, J.K., Jackson, S.H., Bearne, L.M., et al. (2004) Vitamin D Supplementation Improves Neuromuscular Function in Older People Who Fall. Age Aging, 33, 589-595. https://doi.org/10.1093/ageing/afh209

[19] Pfeufer, M., Begerow, B., Minne, H.W., Suppan, K., Fahrleiner-Pammer, A. and Dobnig, H. (2009) Effects of a Long-Term Vitamin D and Calcium Supplementation on Falls and Parameters of Muscle Function in Community-Dwelling Older Individuals. Osteoporosis International, 20, 315-322. https://doi.org/10.1007/s00198-008-0662-7

[20] Kenny, A.M. Biskup, B., Robbins, B., Marcella, G. and Burleson, J.A. (2003) Effect of Vitamin D Supplementation on Strength, Physical Function, and Health Perception in Older, Community-Dwelling Men. Journal of the American Geriatrics Society, 51, 1762-1767. https://doi.org/10.1046/j.1532-5415.2003.51561.x

[21] Brunner, R.L., Cohrane, B., Jackson, R.D., et al. (2008) Calcium, Vitamin D Supplementation, and Physical Function in the Women's Health Initiative. Journal of the American Dietetic Association, 108, 1472-1479. https://doi.org/10.1016/j.jada.2008.06.432

[22] Folstein, M.F., Folstein, S.E. and McHugh, P.R. (1975) "Mini-Mental State". A Practical Method for Grading the Cognitive State of Patients for the Clinician. Journal of Psychiatric Research, 12, 189-198. https://doi.org/10.1016/0022-3956(75)90026-6

[23] Nasredding, Z.S., Phillips, N.A., Bédirian, V., Charbonneau, S., Whitehead, V., Collin, I., Cummings, J.L. and Chertkow, H. (2005) The Montreal Cognitive Assessment, MoCA: A Brief Screening Tool for Mild Cognitive Impairment. Journal of the American Geriatrics Society, 53, 695-699. https://doi.org/10.1111/j.1532-5415.2005.53221.x

[24] Podsiadlo, D. and Richardson, S. (1991) The Timed "UP \& Go": A Test of Basic Functional Mobility for Frail Elderly Persons. Journal of the American Geriatrics Society, 39, 142-148. https://doi.org/10.1111/j.1532-5415.1991.tb01616.x

[25] Gralnik, J.M., Simonsick, E.M., Ferrucci, L., et al. (1994) A Short Physical Perfor- 
mance Battery Assessing Lower Extremity Function: Association with Self-Reported Disability and Prediction of Mortality and Nursing Home Admission. The Journals of Gerontology, 49, M85-M94. https://doi.org/10.1093/geronj/49.2.M85

[26] Quach, L., Galica, A.M., Jones, R.N., Procter-Gray, E., Manor, B., Hannan, M.T., et al. (2011) The Non-Linear Relationship between Gait Speed and Falls: The Maintenance of Balance, Independent Living, Intellect and Zest in the Elderly of Boston Study. Journal of the American Geriatrics Society, 59, 1069-1073.

https://doi.org/10.1111/j.1532-5415.2011.03408.x

[27] Pablo, M. (2017) Vitamin D, A Modulator of Musculoskeletal Health in Chronic Kidney Disease. Journal of Cachexia, Sarcopenia and Muscle, 8, 686-701. https://doi.org/10.1002/jcsm.12218

[28] Tainaka, K., et al. (2002) Fitness-Related Factors Associated with Changes in Walking Speed in Elderly Women. Japanese Journal of Physical Fitness and Sports Medicine, 51, 245-541. https://doi.org/10.7600/jspfsm1949.51.245

[29] Rosenberg, I.H. (1977) Sarcopenia: Origins and Clinical Relevance. The Journal of Nutrition, 127, 990S-991S. https://doi.org/10.1093/jn/127.5.990S

[30] Sanders, K.M., Scot, D. and Ebeling, P.R. (2014) Vitamin D Deficiency and Its Role in Muscle-Bone Interactions in the Elderly. Current Osteoporosis Reports, 12, 74-81. https://doi.org/10.1007/s11914-014-0193-4

[31] Denise, K.H. (2015) Vitamin D and Age-Related Health Outcomes: Movement. Mood and Memory. Current Nutrition Reports, 4, 185-200.

https://doi.org/10.1007/s13668-015-0124-8 